\title{
Mechanical Properties of Concrete with Steel and Polypropylene Fibres at Elevated Temperatures
}

\author{
Josipa Bošnjak ${ }^{1, *}$, Akanshu Sharma ${ }^{2}\left(\mathbb{D}\right.$ and Kevin Grauf ${ }^{3}$ \\ 1 Materials Testing Institute, University of Stuttgart, Pfaffenwaldring 4C, 70569 Stuttgart, Germany \\ 2 Institute of Construction Materials, University of Stuttgart, Pfaffenwaldring 4G, 70569 Stuttgart, Germany; \\ akanshu.sharma@iwb.uni-stuttgart.de \\ 3 University of Stuttgart, 70569 Stuttgart, Germany; kevingrauf@gmx.de \\ * Correspondence: josipa.bosnjak@mpa.uni-stuttgart.de; Tel.: +49-711-685 63377
}

Received: 6 December 2018; Accepted: 16 January 2019; Published: 24 January 2019

\begin{abstract}
Addition of steel fibres to concrete is known to have a significant positive influence on the mechanical properties of concrete. Micro polypropylene (PP) fibres are added to concrete to improve its performance under thermal loads such as in case of fire by preventing the phenomena of explosive spalling. An optimum mixture of steel and micro PP fibres added to concrete may be utilized to enhance both the mechanical and thermal behaviour of concrete. In this work, systematic investigations were carried out to study the influence of elevated temperature on the mechanical properties and physical properties of high strength concrete without and with fibres. Three different mixtures for high strength concrete were used, namely normal concrete without fibres, Steel fibre reinforced concrete and Hybrid fibre reinforced concrete having a blend of hooked end steel fibres and micro PP fibres. The specimens were tested in ambient conditions as well as after exposure to a pre-defined elevated temperature and cooling down to room temperature. For all investigated concrete mixtures the thermal degradation of following properties were investigated: compressive strength, tensile splitting strength, bending strength, fracture energy and static modulus of elasticity. This paper summarizes the findings of the tests performed.
\end{abstract}

Keywords: steel fiber reinforced concrete; polypropylene fibres; elevated temperature; hybrid fibre reinforced concrete; strength; fracture energy

\section{Introduction and State of Art}

Over the past decades, new concrete-based materials are being developed with an aim to derive higher performance than ordinary concrete. Synthetic fibres are added to the concrete mixture to improve one or more of its properties [1], such as creep or impact resistance or to prevent explosive spalling due to fire [2]. In general, the addition of micro PP fibres does not significantly affect the mechanical properties of concrete. Steel fibre reinforced concrete (SFRC) is probably the most investigated fibre reinforced concrete type [3-6]. Due to the inclusion of steel fibres, the tensile strength of concrete gets higher and the fracture behaviour of concrete becomes more ductile $[3,4]$. Inclusion of steel fibres has been proven to reduce the congestion of reinforcement required in the beam-column joint regions according to new seismic design codes [7-9]. Additionally, researchers have tried combining steel fibres with other type of fibres to improve different properties of the concrete mixture $[10,11]$ including the resistance to elevated temperature [12].

Understanding the thermal degradation of various concrete properties is of vital interest for the evaluation of both fire performance and post-fire capacity of RC structures. Furthermore, these data are useful for numerical models, which can then be used to assess the concrete performance upon heating. Significant research has been performed to assure better understanding of the behaviour of 
concrete exposed to elevated temperature, principally for normal and high strength concrete. However, the studies on the thermal behaviour of concrete with steel and/or micro polypropylene (PP) fibres are limited and the majority of the studies focused only on few material properties at a time [13-15].

This work is aimed at studying the mechanical and physical properties of concrete with steel fibres and a combination of steel and PP fibres after exposure to elevated temperatures in residual state. Three different mixtures for high strength concrete are used in these studies, namely:

- NC-Normal concrete without fibres;

- SFRC-Steel fibre reinforced concrete having $50 \mathrm{~kg} / \mathrm{m}^{3}$ of hooked end steel fibres and

- HyFRC-Hybrid fibre reinforced concrete having $50 \mathrm{~kg} / \mathrm{m}^{3}$ of hooked end steel fibres $+1 \mathrm{~kg} / \mathrm{m}^{3}$ of micro PP fibres.

The specimens were tested in ambient conditions as well as in residual conditions after exposure to a pre-defined elevated temperature and cooling down to room temperature. The maximum temperature that was used in the tests was $800{ }^{\circ} \mathrm{C}$. For all investigated concrete mixtures the thermal degradation of following properties were investigated: compressive strength, tensile splitting strength, bending strength, fracture energy and static modulus of elasticity. Different specimens, namely cubes, cylinders, prisms and beams were used to test different properties. However, to optimize and based on the results of the investigations, not all the tests were made for the same temperatures, which will be discussed in the paper. This paper summarizes the findings of the tests performed.

\section{Background}

Concrete is a quasi-brittle material that displays a relatively steep descending branch after reaching the peak load. The fracture behaviour of concrete in tension and the corresponding stress versus crack opening is explained in Figure 1a (adapted from Reinhardt [16]). The response of concrete member in terms of direct tensile stress is plotted as a function of strain in the pre-peak region and in terms of the crack opening displacement in the post-peak region. The stress-strain curve for the concrete under tension is almost linear until the peak-tensile stress (tensile strength of concrete) is reached. The slope of this stress-strain curve in tension up to peak stress is often considered the same as the modulus of elasticity of concrete in compression.

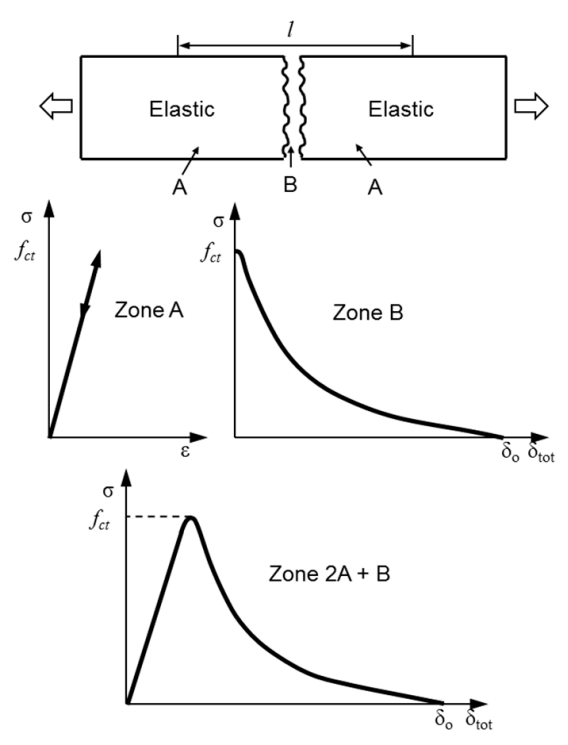

(a) Plain concrete

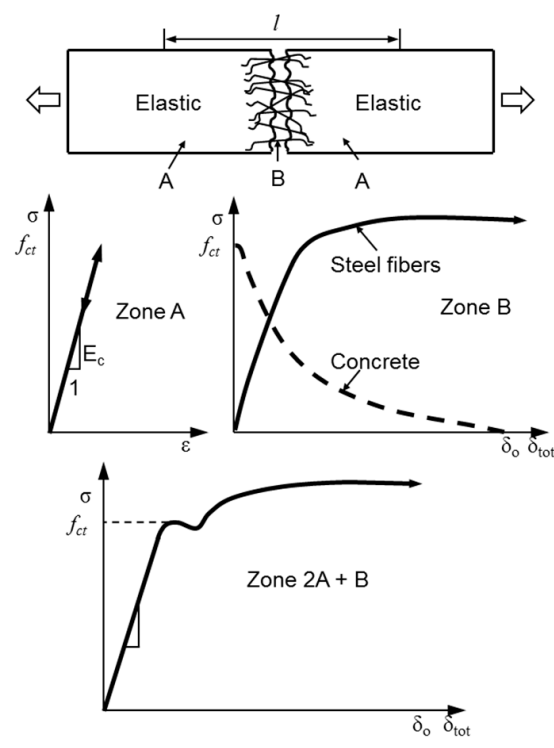

(b) Steel fibre reinforced concrete

Figure 1. Typical fracture behaviour of plain concrete and SFRC under direct tension. 
In case of plain concrete, beyond this peak stress, the crack localizes and therefore instead of average strain over the pre-defined gauge length, crack opening displacement is used to describe the post peak behaviour of concrete under tension. Thus, the tensile response of concrete can be divided in two zones:

- the pre-peak response where the strain over a certain gauge length is used to define the behaviour and

- the post-peak response where the crack opening displacement is used to describe the behaviour.

The post-peak behaviour of plain concrete under tension in stress $\mathrm{v} / \mathrm{s}$ deformation plot resembles an exponential plot. The tensile stress attains the value of zero at a displacement, $\delta_{\mathrm{o}}$.

The fracture behaviour of concrete with steel fibres loaded under direct tension is depicted in Figure $1 \mathrm{~b}$. Steel fibres are activated only after the concrete cracks. At any given displacement, $\delta_{\text {tot }}$ the total resistance of SFRC member is given as the sum of remaining concrete resistance and the resistance offered by the steel fibres intercepted by the crack. Since the concrete resistance drops down rather fast with crack opening, the total resistance is primarily given by the resistance of the fibres. The steel fibres display a relatively ductile behaviour and continue to provide the resistance even at rather high crack opening displacements. This results in a ductile tensile performance of SFRC. The influence of steel fibres on the mechanical properties of concrete under ambient conditions has been significantly investigated and well-reported [14,15,17-19].

When the concrete is exposed to elevated temperature, its mechanical properties decade. For high-strength concrete, one of the major problems encountered in case of exposure to fire is that of explosive spalling. This is due to a combination of pore pressures and thermally induced stresses that cause the concrete to fail abruptly with a sudden release of energy [2]. This type of concrete failure is characterized by bursting and forcible separation of thin layers of concrete, accompanied by a typically loud explosive noise. The failure is progressive in nature, which may lead exposure of reinforcement or prestressing cables to direct fire. Furthermore, it reduces concrete cross section and can thus lead to partial or complete collapse of the structure [2]. The most efficient and popular method to mitigate explosive spalling is the addition of micro polypropylene (PP) fibres in concrete. According to experimental evidence, explosive spalling occurs typically at temperatures between $200{ }^{\circ} \mathrm{C}$ and $250^{\circ} \mathrm{C}[20,21]$, while the PP fibres melt at approximately $160{ }^{\circ} \mathrm{C}$ to $170{ }^{\circ} \mathrm{C}$. Empty or partially empty fibre beds together with the existing concrete capillary pores and micro-cracks form an interconnected porous network in concrete. The created network (e.g., increased permeability) provides free path for the water vapour to escape resulting in a relief of the pore pressure and hence no or very limited spalling occurs. Bošnjak [2] developed a test setup to measure the permeability of concrete at elevated temperatures and used it to measure the influence of micro PP fibres on the permeability of concrete. It was concluded that the addition of PP fibres does not significantly influence the transport properties of concrete up to $80^{\circ} \mathrm{C}$. However, between $80^{\circ} \mathrm{C}$ and $130^{\circ} \mathrm{C}$ concrete with PP fibres exhibits a sudden progressive increase in permeability of approximately two orders of magnitude (Figure 2). Beyond $130{ }^{\circ} \mathrm{C}$ the rate of increase in permeability reduces and it roughly corresponds to that of the concrete without fibres. Same as in the case of concrete without fibres, the residual permeability values of concrete with fibres are found to be somewhat higher than the permeability values at elevated temperatures.

As different types of fibres affect different properties of concrete, an optimal mixture of concrete with a combination of fibre types may lead to an enhanced performance of concrete under different loading conditions (e.g., mechanical + thermal). However, there are often concerns that the addition of polypropylene, though effective in preventing explosive spalling, may result in a negative impact on the mechanical properties of concrete, especially at high temperature. The aim of this experimental study is to investigate the effects of steel and polypropylene fibre reinforcement on the mechanical properties of concrete after exposure to elevated temperatures, in residual conditions. 


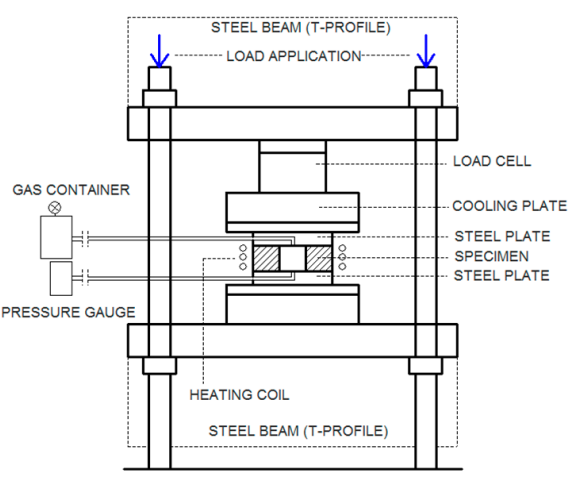

(a) Test setup

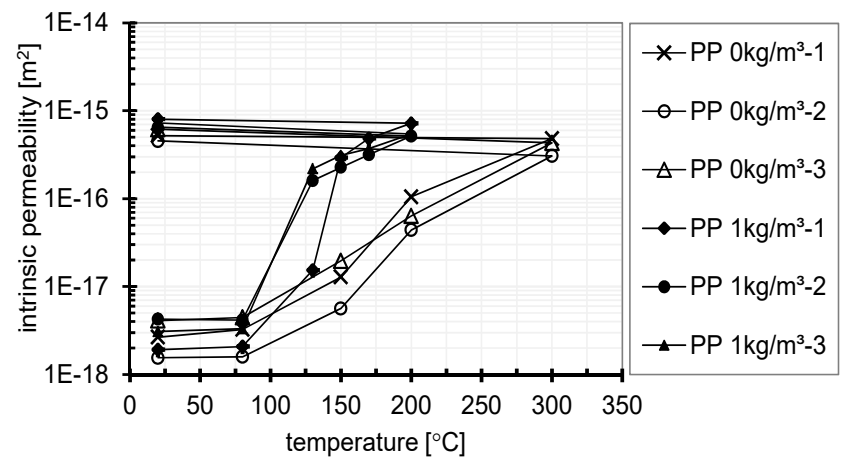

(b) Intrinsic permeability

Figure 2. Permeability of concrete without and with micro PP fibres as a function of temperature, data from [2]. (Note: $1 \mathrm{E}-18$ refers to $1.0 \times 10^{-18}$ ).

\section{Materials and Methods}

\subsection{Concrete Mixture}

In this experimental program, three different concrete mixtures were used, see Table 1. The reference mixture was normal (plain) concrete without fibres (NC) designed to achieve a characteristic target cubic compressive strength of approximately $50 \mathrm{MPa}$. The mixture with steel fibres (SFRC) was made by adding $50 \mathrm{~kg} / \mathrm{m}^{3}$ of steel fibres to the normal concrete mixture, which lies within the typical range used in engineering practice. In order to ensure workability of the mixture, slight adjustments were made to the aggregate content and the amount of super-plasticizer. As a general rule to ensure a sufficient bond between the concrete matrix and fibres, the maximum aggregate size should not exceed one-third of the fibre length. For this reason, the maximum aggregate size of $\mathrm{D}_{\max }=16 \mathrm{~mm}$ and the hooked-end type fibres HE 75/50 by the company ArcelorMittal (Cologne, Germany) were used for SFRC concrete mixture [22]. The tensile strength of fibres was reported by the manufacturer as $1200 \mathrm{~N} / \mathrm{mm}^{2}$. The nominal diameter of the fibre was $\mathrm{d}=0.75 \mathrm{~mm}$ and the nominal fibre length was $\mathrm{L}_{\text {fiber }}=50 \mathrm{~mm}$ (aspect ratio $\mathrm{L}_{\text {fiber }} / \mathrm{d}=67$ ). The third mixture consisted of $50 \mathrm{~kg} / \mathrm{m}^{3}$ of the steel fibres plus $1 \mathrm{~kg} / \mathrm{m}^{3}$ of micro PP fibres (hybrid fibre reinforced concrete-HyFRC). The micro polypropylene fibres of type PB Eurofiber HPR 15/6 with high melt flow rate were used (obtained directly from the producer-baumhueter extrusion $\mathrm{GmbH}$ (Rheda-Wiedenbrück, Germany)). The diameter of the micro PP fibres is 15 microns and the length is $6 \mathrm{~mm}$. These fibres have a superior performance compared to standard micro PP fibres with respect to prevention of explosive spalling. It was shown previously that even a relatively small dosage of HPR $15 / 6$ fibres of $1 \mathrm{~kg} / \mathrm{m}^{3}$ leads to a massive improvement of the resistance to explosive spalling [2]. Increasing the PP fibre content beyond this value is not expected to significantly influence the spalling resistance. However, it may have an adverse effect on the workability and mechanical properties. The target of this work was to investigate the mutual effect of steel fibres (used to enhance the mechanical properties) and micro PP fibres (used to improve resistance to explosive spalling) after exposure to elevated temperatures. Therefore, only one practically relevant dosage of PP fibres was used.

Table 1. Description of concrete mixture used in the test program.

\begin{tabular}{|c|c|c|c|c|c|c|c|c|c|}
\hline $\begin{array}{l}\text { Mixture } \\
\text { ID }\end{array}$ & $\begin{array}{l}\text { Cement } \\
\left(\mathrm{kg} / \mathrm{m}^{3}\right)\end{array}$ & $\begin{array}{c}\text { Sand } \\
\left(\mathrm{kg} / \mathrm{m}^{3}\right)\end{array}$ & $\begin{array}{c}\text { Aggregate } \\
1(2-4 \mathrm{~mm}) \\
\left(\mathrm{kg} / \mathrm{m}^{3}\right)\end{array}$ & $\begin{array}{c}\text { Aggregate } \\
2(4-8 \mathrm{~mm}) \\
\left(\mathrm{kg} / \mathrm{m}^{3}\right)\end{array}$ & $\begin{array}{c}\text { Aggregate } 3 \\
(8-16 \mathrm{~mm}) \\
\left(\mathrm{kg} / \mathrm{m}^{3}\right)\end{array}$ & $\begin{array}{c}\text { Water/Cement } \\
\text { Ratio (-) }\end{array}$ & $\begin{array}{l}\text { Superplasticizer } \\
\text { ( } \% \text { of cement) }\end{array}$ & $\begin{array}{c}\text { Steel } \\
\text { Fibres } \\
\left(\mathrm{kg} / \mathrm{m}^{3}\right)\end{array}$ & $\begin{array}{c}\text { Micro PP } \\
\text { Fibres } \\
\left(\mathrm{kg} / \mathrm{m}^{3}\right)\end{array}$ \\
\hline $\mathrm{NC}$ & 370 & 562 & 259 & 392 & 571 & 0.48 & 0.2 & 0 & 0 \\
\hline SFRC & 370 & 556 & 256 & 389 & 565 & 0.48 & 0.3 & 50 & 0 \\
\hline HyFRC & 370 & 556 & 256 & 389 & 565 & 0.48 & 0.4 & 50 & 1 \\
\hline
\end{tabular}




\subsection{Test Specimen}

Different properties of concrete were tested in this study, for which different test specimen were utilized. For each property and a given temperature, at least two specimens were tested to verify the repeatability of the test results. The test specimens used to obtain different material properties are summarized in Table 2.

Table 2. Description of the test specimen used to determine material properties.

\begin{tabular}{ccc}
\hline Material property & Specimen Type & Specimen Dimensions \\
Compressive strength & Cube & $150 \mathrm{~mm} \times 150 \mathrm{~mm} \times 150 \mathrm{~mm}$ \\
Split tensile strength & Cylinder & $150 \mathrm{~mm}(\mathrm{D}) \times 300 \mathrm{~mm}(\mathrm{H})$ \\
$\begin{array}{c}\text { Flexural tensile strength } \\
\text { Fracture energy } \\
\begin{array}{c}\text { Static modulus of } \\
\text { elasticity }\end{array} \\
\begin{array}{c}\text { Dynamic modulus of } \\
\text { elasticity }\end{array}\end{array}$ & $\begin{array}{c}\text { Notched beam } \\
\text { Notched beam }\end{array}$ & $\begin{array}{c}150 \mathrm{~mm} \times 150 \mathrm{~mm} \times 600 \mathrm{~mm} \\
\text { Central notch: } 5 \mathrm{~mm} \text { wide and } \\
50 \mathrm{~mm} \mathrm{high}\end{array}$ \\
\hline
\end{tabular}

\subsection{Heat Treatment}

The mechanical properties of different types of concretes were investigated over a range of $20^{\circ} \mathrm{C}$ (ambient conditions) until $600^{\circ} \mathrm{C}, 700^{\circ} \mathrm{C}$ or $800^{\circ} \mathrm{C}$ depending on the property investigated. For heating, the test specimens were placed inside an electric oven with programmable controls for the heating rate as well as retention time for the temperature. The target temperature in each case was reached at a relatively slow heating rate of $2{ }^{\circ} \mathrm{C} / \mathrm{min}$. After reaching the desired temperature, the temperature was maintained for $3 \mathrm{~h}$ to ensure uniform heating of the test specimen. The temperature was allowed to gradually come down after the completion of retention time by opening the small ventilation holes in the oven, while keeping the oven door closed. When the oven temperature reached approximately $100^{\circ} \mathrm{C}$, the door of the oven was opened to allow relatively fast cooling. Note that all the tests were performed on the cooled down specimen (residual state).

\section{Test Results and Discussion}

\subsection{General}

In this section, the results of the experiments performed are presented. In all the cases, after heat treatment, the specimens were visually inspected for any surface cracks, which were then marked in red colour. The specimens were tested under static loading rate. All concrete types were tested at a similar age of approximately 5-6 months. Following material properties were investigated: compressive strength, splitting strength, bending strength, fracture energy, dynamic modulus of elasticity (non-destructive impact-echo test method) and static modulus of elasticity. While evaluating the results of the present study, it should be kept in mind that only two specimens were tested per case (only in exceptional cases three or more).

In the present study only one dosage of both steel and polypropylene fibres was investigated. Therefore, the results and conclusions presented herein are indicative and valid only for the conditions used in this study. Further studies are required to allow more general conclusions. In particular, more detailed studies are required to investigate the thermal degradation of SFRC with different fibre content and fibre types (straight and corrugated steel fibres). 


\subsection{Compressive Strength}

The compressive strength of concrete was obtained from a standard compressive strength test using cube specimens of side $150 \mathrm{~mm}$ following the European testing standard (EN) 12390-3 [23]. Figure 3 presents the typical thermal cracks observed on the surface of the specimens after heat treatment with a maximum temperature of $600{ }^{\circ} \mathrm{C}$ and a typical failure mode after the compressive strength test. Due to relatively slow heating, the cracks appearing on the surface were rather fine. The failure mode observed in the compressive strength test performed on the cubes after heat treatment corresponds well with the failure modes observed for cubes tested under ambient conditions. Thus, the exposure to elevated temperature does not result in a change of failure mode.

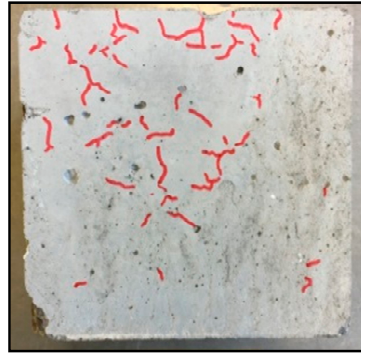

$\mathrm{NC}$

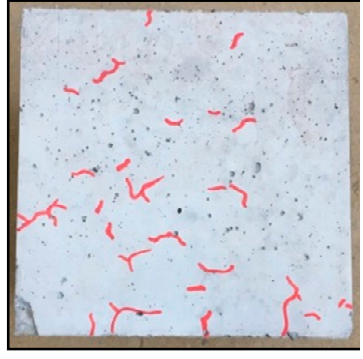

SFRC

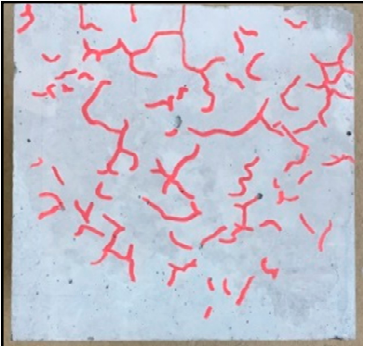

HyFRC

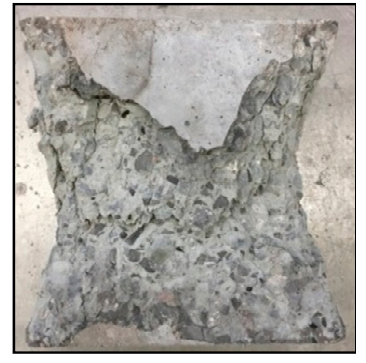

Failure mode

Figure 3. Thermal cracks and typical failure mode observed for the cubes used for compressive strength tests after an exposure to maximum temperature of $600{ }^{\circ} \mathrm{C}$.

The compressive strength tests were performed on cubes with a maximum exposure temperature of $800{ }^{\circ} \mathrm{C}$. The results of the mean compressive strength of different concrete mixtures obtained from the tests are plotted as a function of the exposure temperature in Figure 4a. In general, it can be observed that the inclusion of steel and micro PP fibres does not have any significant influence on the mean compressive strength of concrete. This can be attributed to the relatively low volumetric fraction of fibres in concrete. Nevertheless, it is found that the addition of micro PP fibres does not negatively influence the compressive strength of concrete, neither at ambient, nor at elevated temperature. It was further observed that the reduction in compressive strength for all the mixtures tested was rather strong for an exposure temperature of $800{ }^{\circ} \mathrm{C}$. The scatter of test results within a particular test series was found to be rather low independent of the concrete type and exposure temperature, as visible in Table 3. The fibre-reinforced concrete types exhibit similar scatter as the normal concrete. With increasing temperature, the scatter increases slightly for all three concrete types. This is most probably related to the pronounced effect of concrete heterogeneity, which then affects thermally induced damage.

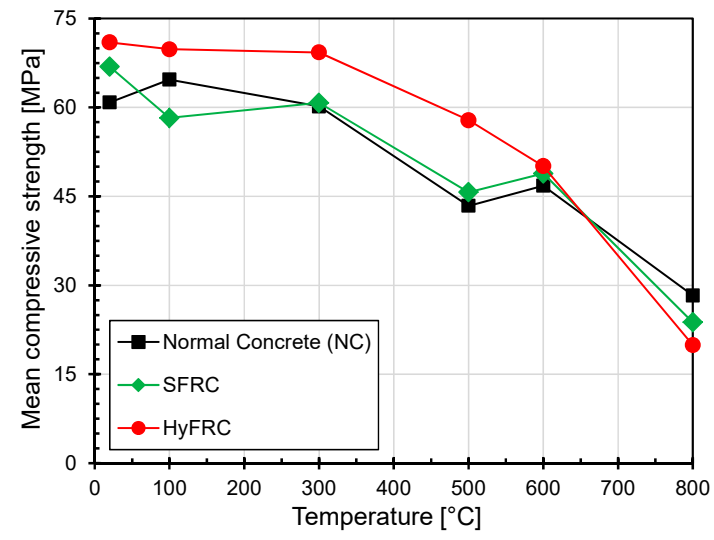

(a) Absolute values

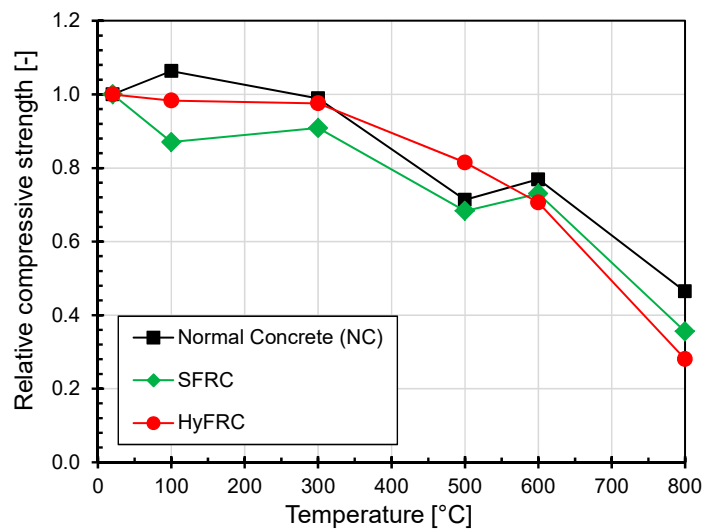

(b) Relative values

Figure 4. Influence of elevated temperature on compressive strength of different types of concrete. 
The variation of the relative compressive strength with temperature as shown in Figure $4 \mathrm{~b}$ follows similar trend for all three concrete mixtures tested. The compressive strength remains almost constant up to approximately $300^{\circ} \mathrm{C}$. As the difference in thermal strain of the concrete matrix and aggregates increases, the compressive strength decreases linearly. After exposure to $800{ }^{\circ} \mathrm{C}$ normal concrete exhibits slightly higher residual compressive strength than the fibre reinforced concrete types. This is attributed to the scatter in the material properties of concrete. Thus, it can be concluded that the influence of elevated temperature on the compressive strength of concrete with added steel fibres as well with added steel and micro PP fibres is the same as that on the compressive strength of normal concrete. These results lead to an important conclusion that addition of micro PP fibres can prevent explosive spalling of concrete without leading to any deterioration of the compressive strength of concrete.

Table 3. Overview of the test results.

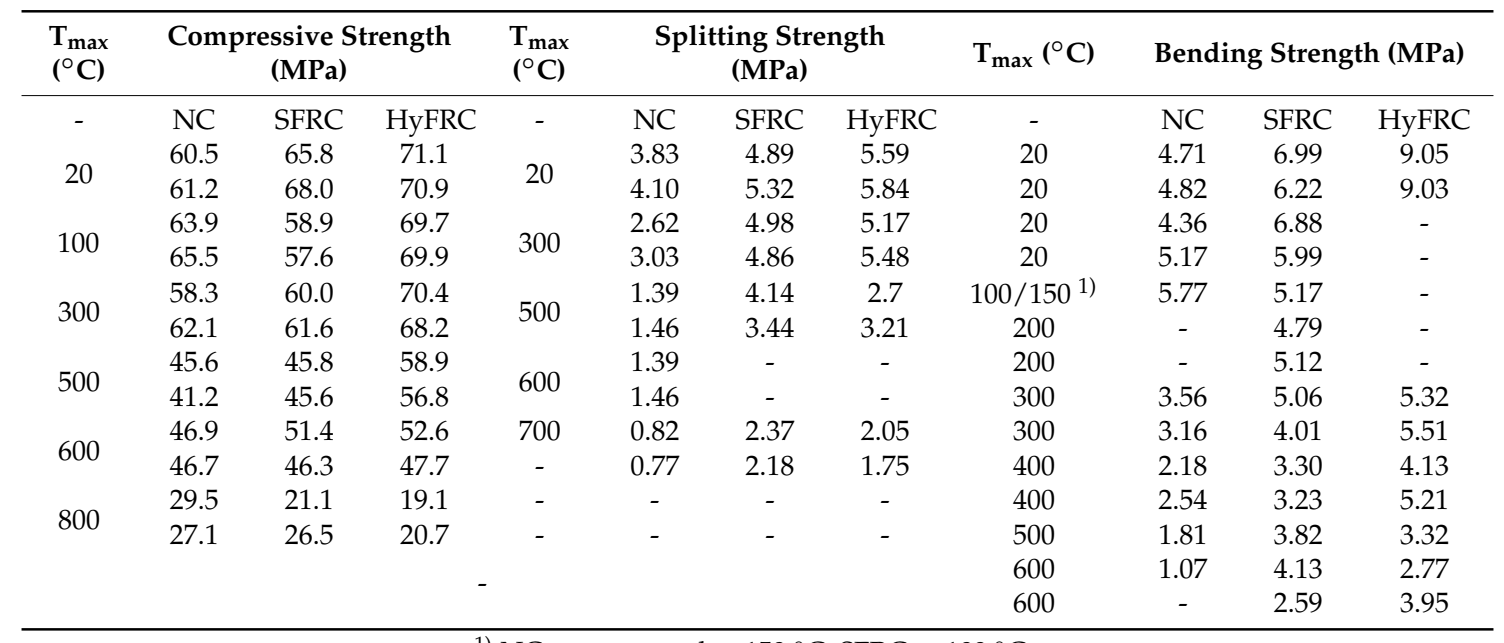

1) NC was exposed to $150{ }^{\circ} \mathrm{C}$; SFRC to $100^{\circ} \mathrm{C}$.

\subsection{Split Tensile Strength}

The split tensile strength was obtained by performing standard Brazilian tests according to EN 12390-6 [24], on concrete cylinders $150 \mathrm{~mm}$ in diameter and $300 \mathrm{~mm}$ high. Again, prior to mechanical loading, thermal cracks were marked on the surface. Figure 5 displays the typical thermal cracks visible on the surface of the cylinders used for split tension tests after heating to $600{ }^{\circ} \mathrm{C}$ and cooling down to room temperature. Several fine cracks were seen on the surface due to slow heating. Figure 6 shows the test setup used for the split tension tests and a typical failure mode obtained from the tests.

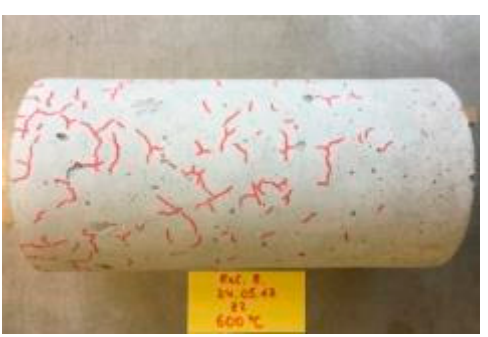

NC

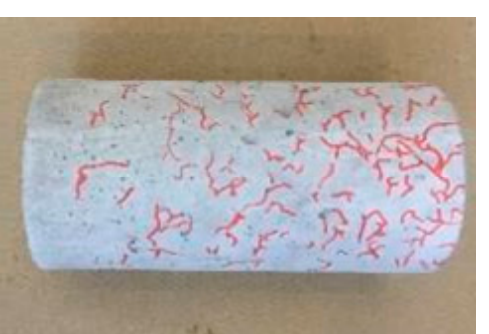

SFRC

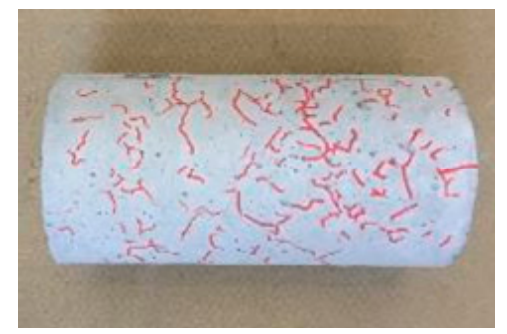

HyFRC

Figure 5. Typical thermal cracks observed for the cylinders used for split tensile strength tests after exposure to maximum temperature of $600^{\circ} \mathrm{C}$. 


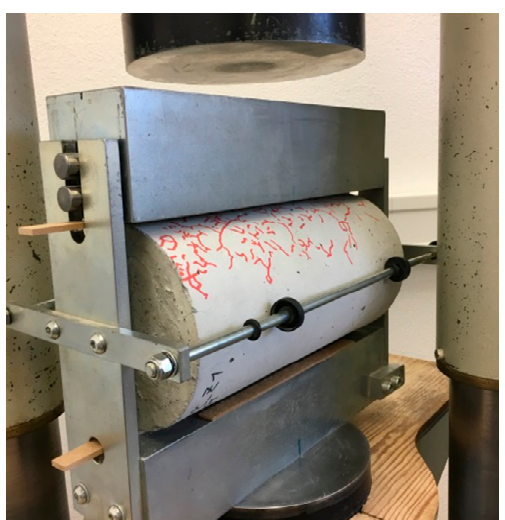

(a)

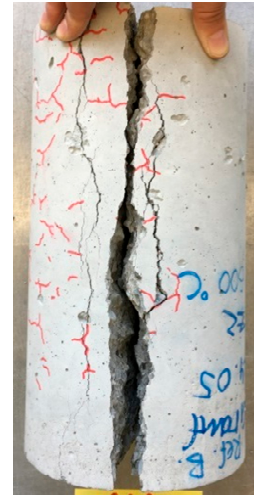

(b)

Figure 6. (a) Test setup and (b) typical failure mode of concrete cylinders used for determining split tensile strength after exposure to a temperature of $600{ }^{\circ} \mathrm{C}$.

The mean value and the relative degradation of the split tensile strength obtained from the tests for different types of concrete is plotted as a function of the exposure temperature in Figure 7. As expected, the influence of the presence of steel and micro PP fibres on split tensile strength is significantly higher than that on the compressive strength of concrete. This is explainable by the fact that as the concrete cracks in tension, the fibres crossing the crack plane get activated and provide resistance to failure due to splitting. For the temperature range investigated $\left(20\right.$ to $\left.700{ }^{\circ} \mathrm{C}\right)$, the tensile strength of SFRC and HyFRC was around $40 \%$ to $150 \%$ higher than that of normal concrete. This shows a high beneficial influence of steel and micro PP fibres on tensile strength of concrete even at elevated temperatures.

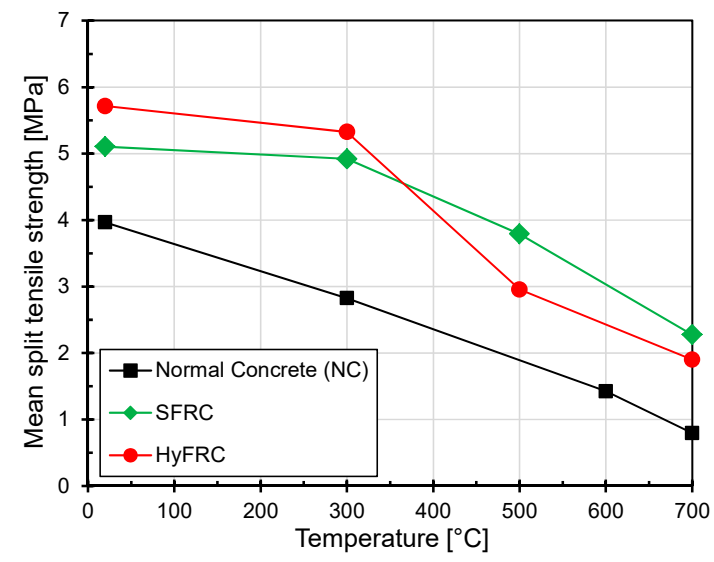

(a) Absolute values

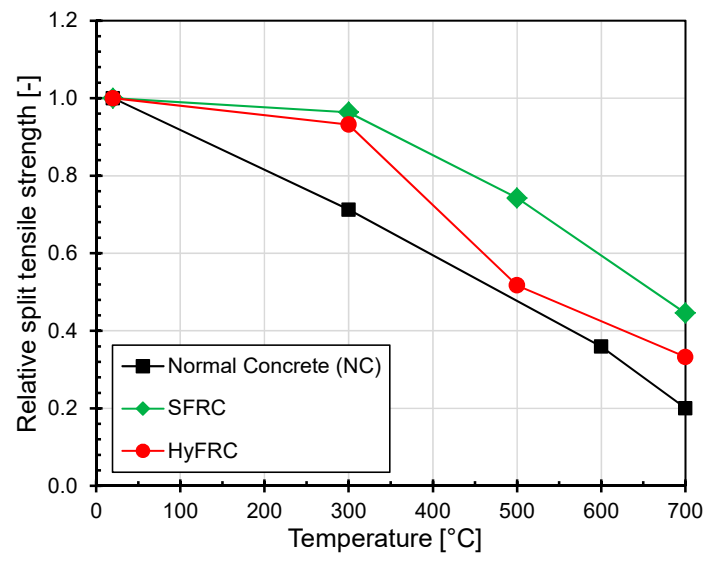

(b) Relative values

Figure 7. Influence of elevated temperature on split tensile strength of different types of concrete.

\subsection{Flexural Tensile Strength (Modulus of Rupture) and Fracture Energy}

The flexural tensile strength or modulus of rupture of concrete was measured in accordance with RILEM 50-FMC Recommendation [25] using notched prismatic beam specimens with a cross-section of $150 \mathrm{~mm} \times 150 \mathrm{~mm}$ and a span length of $600 \mathrm{~mm}$. A notch of $5 \mathrm{~mm}$ width and $50 \mathrm{~mm}$ length was cut at the mid span of the beams. Figure 8 shows the test setup used in the flexural tests as well as the typical failure mode obtained for beams with SFRC. Note that the same test was used to evaluate the fracture energy of concrete as well. The tests were performed in crack tip opening displacement (CTOD) control. 


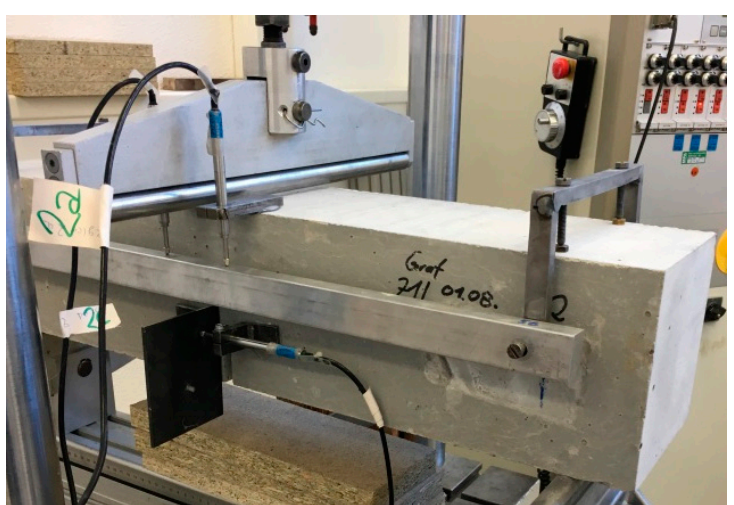

(a)

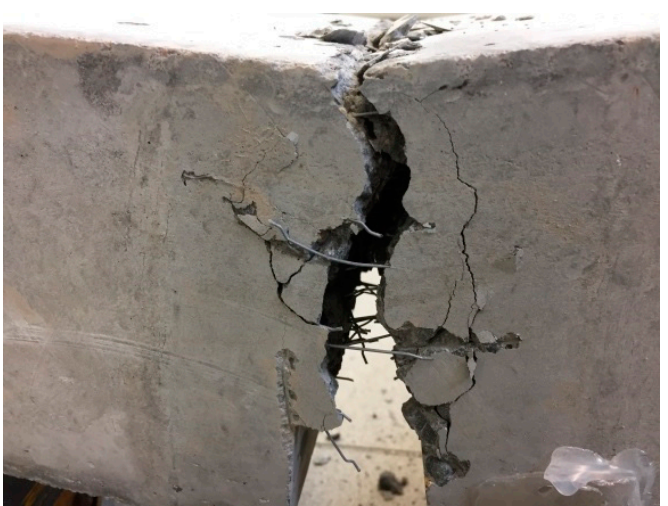

(b)

Figure 8. (a) Test setup used and (b) close up view of the typical fracture region (failure mode) observed in the flexural tests on notched beams.

The typical load-displacement curves obtained from the flexural tests on notched beams are plotted in Figure 9 for different concretes (a) under ambient conditions and (b) after exposure to a temperature of $400{ }^{\circ} \mathrm{C}$ in residual conditions. The load-displacement curves for normal concrete displays a relatively straight pre-peak line, a well-defined peak and a gradual post-peak softening curve, typically associated with the tensile behaviour of normal concrete. The load-displacement curve for normal concrete retains its shape also after exposure to elevated temperature but reaching a lower ultimate load. However, the sharpness of the peak is reduced and the post-peak softening becomes more gradual for normal concrete loaded after exposure to elevated temperature.

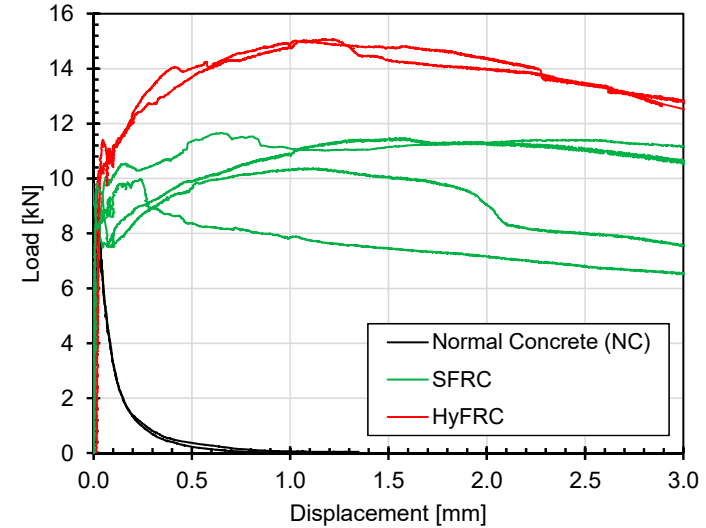

(a) Ambient conditions $\left(20^{\circ} \mathrm{C}\right)$

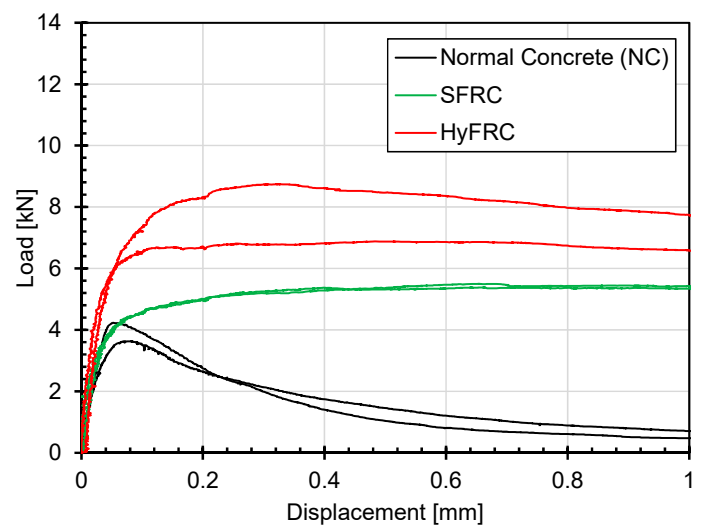

(b) Residual $\left(400^{\circ} \mathrm{C}\right)$

Figure 9. Load-displacement curves obtained from the flexural tests on notched beams.

Conversely, the load-displacement curves obtained for concrete with steel fibres (SFRC) as well as the concrete with a combination of steel and micro PP fibres (HyFRC) under ambient conditions display a first drop in the load at approximately the same load as the peak load obtained for normal concrete. After this first drop, the load carrying capacity further rises and a high level of load is maintained even at relatively large displacements. This phenomenon is associated with the tension behaviour of concrete with steel fibres and is discussed in Figure 1 of this paper. It is interesting to observe that even though the micro PP fibres are not expected to contribute much towards the strength, the peak load reached for the concrete with both steel and micro PP fibres was significantly higher than SFRC. This is, however, attributed to the higher concrete strength of HyFRC. It can be observed in Figure 9a that only the cracking strength of HyFRC is higher than that of SFRC. The post-cracking behaviour is similar for both SFRC and HyFRC. These results indicate that the tensile post-cracking behaviour is mainly influenced by the steel fibres and not by PP fibres. 
The performance of SFRC and HyFRC in residual conditions after exposure to a temperature of $400{ }^{\circ} \mathrm{C}$ was also significantly better than the performance of normal concrete. Both the strength as well as displacement capacity were found to be rather large compared to the corresponding values obtained for normal concrete. Thus, it can be said that the beneficial influence of adding steel and micro PP fibres as observed under ambient conditions remain valid even after exposure to elevated temperatures.

Figure 10a displays the influence of elevated temperature on the flexural tensile strength of different types of concrete. The concrete with both steel and micro PP fibres displays the highest strength values for almost all the exposure temperatures. The trend of the flexural tensile strength is comparable to that obtained for splitting tensile strength (Figure 7a). It may be noted that the slight increase in the flexural strength of $\mathrm{NC}$ after exposure to $150{ }^{\circ} \mathrm{C}$ is probably attributable to the increased concrete age at testing compared to all other specimens (concrete age 9 months).

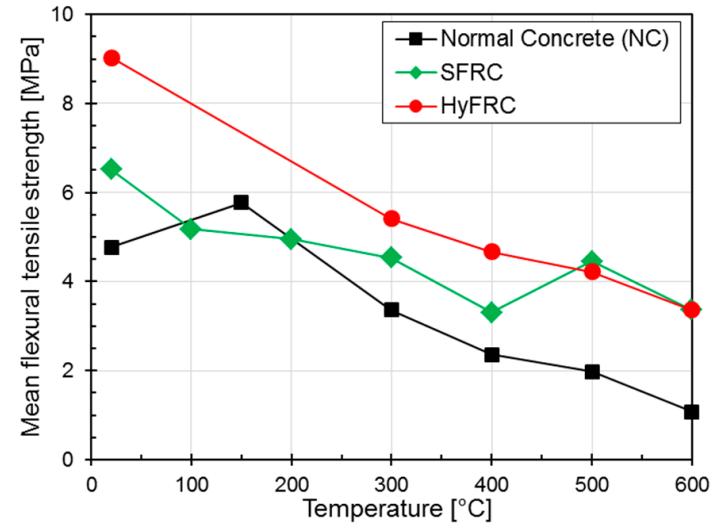

(a) Flexural tensile strength

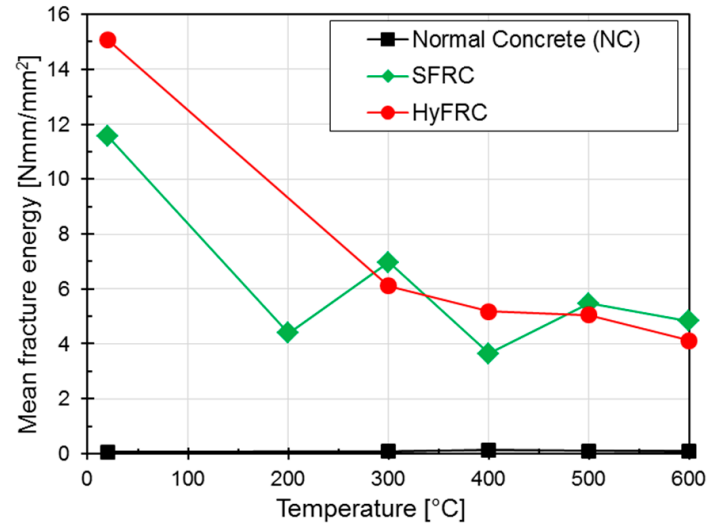

(b) Fracture energy

Figure 10. Variation of flexural tensile strength and fracture energy as a function of exposure temperature.

The fracture energy values of different concretes were calculated as the area under load-CMOD (crack mouth opening displacement) curves. Figure 10b shows the variation of fracture energy as a function of exposure temperature calculated for different concretes tested. Irrespective of the exposure temperature, the fracture energy of normal concrete $(\mathrm{NC})$ was found to be negligible compared to that of SFRC or HyFRC. This can be observed by comparing the load-displacement curves obtained for different concretes (Figure 9), where the area under the curves for normal concrete is negligible compared to the area under the curves for concrete with fibres. The steel fibres contribute to high increase in fracture energy under ambient conditions. With increasing temperature the bond between steel fibres and concrete undergoes thermally induced damage, which then leads to a significantly lower fracture energy. Already after exposure to $300^{\circ} \mathrm{C}$, the fracture energy of fibre reinforced concrete reduces to more than half of the initial value (under ambient conditions). Beyond this temperature, the fracture energy decreases only moderately. This trend is different from that observed in normal concrete, which exhibits an increase in fracture energy up to $300-400{ }^{\circ} \mathrm{C}$ (up to $50-60 \%$ ). Residual fracture energy after exposure to $600^{\circ} \mathrm{C}$ of normal concrete corresponds roughly to that under ambient conditions. These results are consistent with those reported in literature [26].

In order to obtain more insight into the ductility of fibre reinforced concrete after exposure to elevated temperatures, an evaluation of the residual flexural load for different CMOD values (first cracking, 0.5, 1.5, 2.5, 3.5 and $10.0 \mathrm{~mm}$ ) was performed. The results are summarized in Figure 11. The relative flexural load represents the ratio of the flexural load corresponding to the measured CMOD and the load at the proportionality limit. According to the European standard EN 14651 [27] the proportionality limit is estimated as the maximum load attained before or upon reaching a CMOD of $0.05 \mathrm{~mm}$. However, considering that this limit would not be realistic for thermally damaged concrete, the limit of proportionality was estimated as the maximum load attained up to a CMOD of $0.1 \mathrm{~mm}$. 
In spite of the pronounced scatter, it can be observed in Figure 11 that the relative ductility of both fibre reinforced concrete types is not significantly influenced by the temperature.

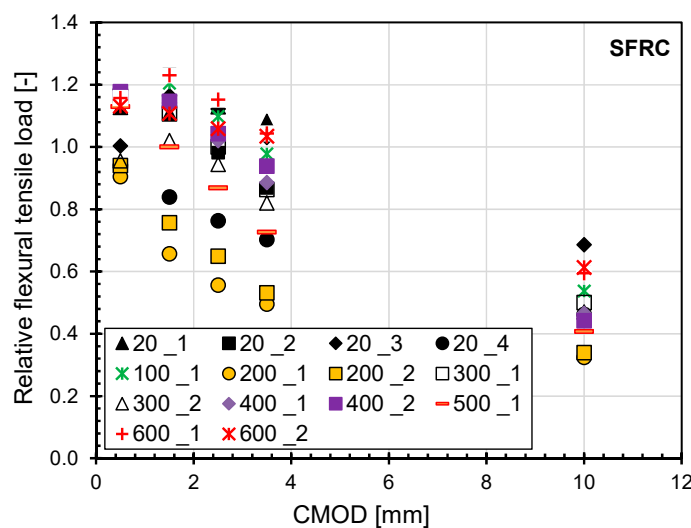

(a)

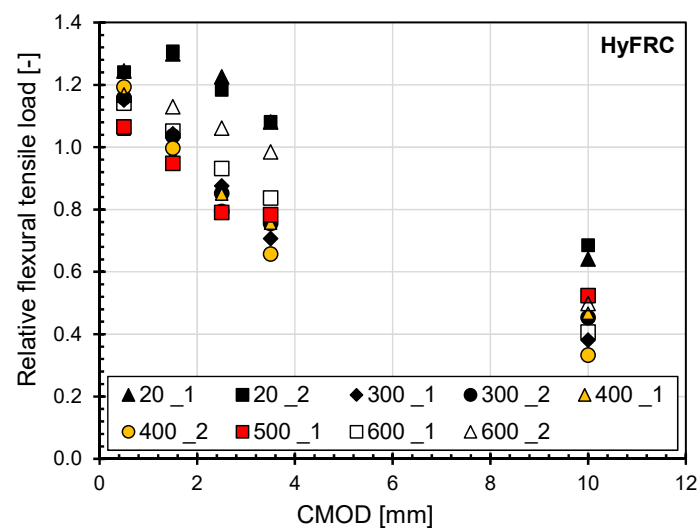

(b)

Figure 11. Influence of elevated temperature on the ductility of (a) SFRC and (b) HyFRC.

\subsection{Static Modulus of Elasticity}

The static modulus of elasticity was obtained in accordance with EN 12390-13 [28] using the prismatic specimens of size $100 \mathrm{~mm} \times 100 \mathrm{~mm}$ in cross-section and $200 \mathrm{~mm}$ in height. The typical test setup as well as the variation of the static modulus of elasticity as a function of temperature for different types of concrete investigated is plotted in Figure 12. Only fine cracks were observed o the surface due to thermal loading, which were marked. The plot of the static modulus of elasticity as a function of temperature clearly shows that the absolute values as well as the variation of the elasticity modulus the temperature for SFRC and HyFRC are quite similar to that of normal concrete. Considering the relatively low volumetric content of the fibres in concrete, it can be expected that the fibres do not have any significant effect on the modulus of elasticity.

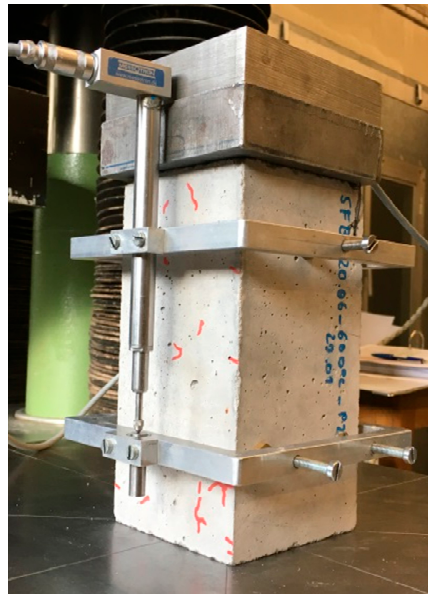

(a)

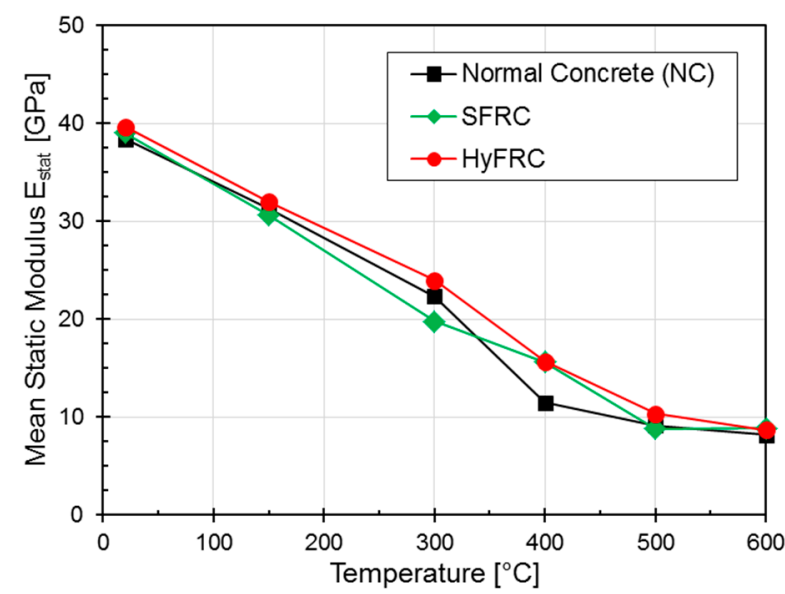

(b)

Figure 12. (a) Typical test setup and (b) variation of static modulus of elasticity with elevated temperature for different types of concrete.

\section{Conclusions}

In this work, systematic experimental investigations were carried out to study the influence of elevated temperature on the mechanical properties of concrete without fibres, SFRC-Steel fibre reinforced concrete having $50 \mathrm{~kg} / \mathrm{m}^{3}$ of hooked end steel fibres and HyFRC - Hybrid fibre reinforced 
concrete having $50 \mathrm{~kg} / \mathrm{m}^{3}$ of hooked end steel fibres $+1 \mathrm{~kg} / \mathrm{m}^{3}$ of micro PP fibres. The test results led to the following conclusions:

1. The compressive strength of SFRC and HyFRC was found to be comparable to that of NC for entire temperature range, which is related to the relatively low volumetric content of fibres in concrete.

2. The split tensile strength as well as the modulus of rupture (flexural tensile strength) for concrete with fibres (both SFRC and HyFRC) was significantly higher than that of NC for all the temperatures. An increase in strength of the order of $40 \%$ to $150 \%$ was observed due to the presence of the fibres. The increase is primarily owed to the relatively high content of hooked-end steel fibres, which can take up the load upon concrete cracking. However, the bond between steel fibres and concrete is damaged due to thermal exposure, resulting in a decay of tensile strength with increasing temperature.

3. The highest influence of the presence of fibres was observed in the fracture energy of concrete. For both SFRC and HyFRC, the fracture energy was at least two orders of magnitude higher than that of $\mathrm{NC}$ over the entire temperature range investigated in this work.

4. The static modulus of elasticity of all types of concrete investigated is of similar magnitude and the variation with the temperature is also similar. The addition of fibres cannot affect elasticity modulus due to their small volumetric content.

5. No negative influence of the presence of $1 \mathrm{~kg} / \mathrm{m}^{3}$ of micro PP fibres was observed on the strength, fracture energy or modulus of elasticity of concrete with steel fibres.

6. Such hybrid FRC has a huge potential in real-life applications to provide high mechanical as well as fire resistance.

Author Contributions: J.B. and A.S. conceived and designed the experiments; J.B. and K.G. performed the experiments and analyzed the data; J.B. and A.S. wrote the paper.

Funding: This research received no external funding.

Acknowledgments: The authors are very thankful to the company ArcelorMittal Wire Solutions Sales Germany $\mathrm{GmbH}$ for providing the steel fibres and to company baumhueter extrusion $\mathrm{GmbH}$ for providing the polypropylene fibres.

Conflicts of Interest: The authors declare no conflict of interest.

\section{References}

1. Khan, M.I.; Abbas, Y.M.; Fares, G. Review of high and ultrahigh performance cementitious composites incorporating various combinations of fibres and ultrafines. J. King Saud Univ. Eng. Sci. 2017, 29, 339-347.

2. Bosnjak, J. Explosive Spalling and Permeability of High Performance Concrete under Fire-Numerical and Experimental Investigations. Ph.D. Thesis, University of Stuttgart, Stuttgart, Germany, 2014.

3. Jang, S.J.; Yun, H.D. Combined effects of steel fibre and coarse aggregate size on the compressive and flexural toughness of high-strength concrete. Compos. Struct. 2018, 185, 203-211. [CrossRef]

4. Behnood, A.; Verian, K.P.; Gharehveran, M.M. Evaluation of the splitting tensile strength in plain and steel fibre-reinforced concrete based on the compressive strength. Constr. Build. Mater. 2015, 98, 519-529. [CrossRef]

5. Kooiman, A.G. Modelling Steel Fibre Reinforced Concrete for Structural Design. Ph.D. Thesis, TU Delft, Delft, The Netherlands, 2000.

6. Hanna, A.N. Steel Fiber Reinforced Concrete Properties and Resurfacing Applications; Report RD049.01P; Portland Cement Association: Skokie, IL, USA, 1977.

7. Abbas, A.A.; Mohsin, S.M.S.; Cotsovos, D.M. Seismic response of steel fibre reinforced concrete beam-column joints. Eng. Struct. 2014, 59, 261-283. [CrossRef]

8. Filiatrault, A.; Pineau, S.; Houde, J. Seismic behaviour of steel fibre-reinforced concrete interior beam-column joints. ACI Struct. J. 1995, 92, 543-552. 
9. Liu, C. Seismic Behavior of Beam-Column Joint Subassemblies Reinforced with Steel Fibers. Master's Thesis, Department of Civil Engineering, University of Canterbury Christchurch, Christchurch, New Zealand, 2006.

10. Chidambaram, R.S.; Agarwal, P. Seismic behaviour of hybrid fibre reinforced cementitious composite beam-column joints. Mater. Design 2015, 86, 771-781. [CrossRef]

11. Sharma, A.; Reddy, G.R.; Varshney, L.; Kumar, H.B.; Vaze, K.K.; Ghosh, A.K.; Kushwaha, H.S.; Krishnamoorthy, T.S. Experimental investigations on mechanical and radiation shielding properties of hybrid lead-steel fibre reinforced concrete. Nuclear Eng. Design 2009, 239, 1180-1185. [CrossRef]

12. Horiguchi, T.; Sugawara, T.; Saeki, N. Fire resistance of hybrid fibre reinforced high strength concrete. In Proceedings of the 6th RILEM symposium on Fiber Reinforced Concretes (FRC)—BEFIB 2004, Varenna, Italy, 20-22 September 2004.

13. Caggiano, A.; Gambarelli, S.; Martinelli, E.; Nistico, N.; Pepe, M. Experimental characterization of the postcracking response in Hybrid Steel/Polypropylene Fiber-Reinforced Concrete. Constr. Build. Mater. 2016, 125, 1035-1043. [CrossRef]

14. Poon, C.S.; Shui, Z.H.; Lam, L. Compressive behaviour of fibre reinforced high-performance concrete subjected to elevated temperatures. Cement Concr. Res. 2004, 34, 2215-2222. [CrossRef]

15. Pliya, P.; Beaucour, A.L.; Noumowé, A. Contribution of cocktail of polypropylene and steel fibres in improving the behaviour of high strength concrete subjected to high temperature. Constr. Build. Mater. 2011, 25, 1926-1934. [CrossRef]

16. Reinhardt, H.-W. Werkstoffe des Bauwesens (Building materials). In Der Ingenieurbau; Mehlhorn, G., Ed.; Ernst \& Sohn: Berlin, Germany, 1997; pp. 1-163. (In Germany)

17. Balaguru, P.N.; Shah, S.P. Fiber-Reinforced Cement Composites; McGraw-Hill: New York, NY, USA, 1992; ISBN 00705640009780070564008.

18. American Concrete Institute Committee 544. State-of-the-Art Report on Fiber Reinforced Concrete; American Concrete Institute: Farmington Hills, MI, USA, 2009.

19. British Standard Institution. BS EN 14889-1, Fibres for Concrete, Part 1. Steel Fibres-Definition; British Standard Institution: London, UK, 2006.

20. International Federation for Structural Concrete (fib). fib Model Code for Concrete Structures 2010; International Federation for Structural Concrete: Lausanne, Switzerland, 2013.

21. Khoury, G.; Anderberg, Y. Concrete Spalling Review; Swedish National Road Administration: Borlänge, Sweden, 2000.

22. National Road Administration. Technical Data Sheet: Hooked-End Steel Fibers HE 75/35, ArcelorMittal. 2000. Available online: http://ds.arcelormittal.com/wiresolutions/steelfibres/products/hooked_end_ fibres_he/language/EN (accessed on 7 April 2017).

23. EN 12390:3 Testing Hardened Concrete_Part 3: Compressive Strength of Test Specimens; European Committee for Standardization: Brussels, Belgium, 2009.

24. EN 12390:6 Testing Hardened Concrete-Part 6: Tensile Splitting Strength of Test Specimens; European Committee for Standardization: Brussels, Belgium, 2009.

25. RILEM TC-50 FMC (Draft Recommendation). Determination of the fracture energy of mortar and concrete by means of three-point bend tests on notched beams. Mater. Struct. 1985, 18, 285-290.

26. Zhang, B.; Bicanic, N. Residual Fracture Toughness of Normal- and High Strength Gravel Concrete after Heating to $600{ }^{\circ} \mathrm{C}$. ACI Mater. J. 2002, 99, 217-226.

27. EN 14651 Test Method for Metallic Fibre Concrete-Measuring the Flexural Tensile Strength (Limit or Proportionality (LOP), Residual); European Committee for Standardization: Brussels, Belgium, 2005.

28. EN 12390:13 Testing Hardened Concrete-Part 13: Determination of Secant Modulus of Elasticity in Compression; European Committee for Standardization: Brussels, Belgium, 2013.

(C) 2019 by the authors. Licensee MDPI, Basel, Switzerland. This article is an open access article distributed under the terms and conditions of the Creative Commons Attribution (CC BY) license (http://creativecommons.org/licenses/by/4.0/). 